\title{
ENSINO DA CADEIA PRODUTIVA DA CARNE OVINA E CAPRINA: RELATO DE EXPERIÊNCIA DE UMA PRÁTICA PEDAGÓGICA NO ENSINO REMOTO
}

\section{TEACHING THE PRODUCTION CHAIN OF SHEEP AND GOAT MEAT: REPORT OF AN EXPERIENCE OF A PEDAGOGICAL PRACTICE IN REMOTE EDUCATION}

Francisca Giselle da Cruz¹, Maria Aparecida Ferreira Barbosa Fernandes², Marcia Leyla de Freitas Macedo Felipe $^{3}$, Daniela Glicea Oliveira da Silva ${ }^{4}$, Priscila Izidro de Figueirêdo ${ }^{5}$

Submetido em: 26/03/2021

Aprovado: 15/04/2021

\section{RESUMO}

O objetivo deste artigo consiste em relatar sobre as vivências em docência, oriundos da cadeia produtiva da carne ovina e caprina, por intermédio de uma reunião assíncrona do Grupo de Pesquisa. $O$ estudo caracterizou-se como qualitativo e descritivo, sendo relatadas práticas exitosas de ensino da disciplina Tecnologia de Produtos de Origem Animal I, TPOA 1. Contudo, a cadeia da caprinovinocultura no Brasil encontra-se desorganizada, falta uma padronização dos animais a serem destinados ao abate e a clandestinidade ainda é bastante considerada para esta operação, o que pode ocasionar danos à saúde pública, caso haja o consumo dessas carnes desprovidas de inspeção sanitária. Desta forma, a cadeia produtiva da carne ovina e caprina consiste nas seguintes etapas: obtenção de insumos; produção; processamento; distribuição/consumo; e consumidor. Evidenciou-se, durante a elaboração do presente artigo, relatos de experiências exitosas, no elo do processamento. Devido a pandemia do novo Coronavírus, o relato de vivência em docência sobre o assunto em questão ganhou um novo formato, via atividade remota, que possibilita a inserção das plataformas educacionais digitais, de forma a manter o interesse e o envolvimento dos discentes.

PALAVRAS-CHAVE: Atividade educacional remota. Covid-19. Ferramentas digitais.

\begin{abstract}
The objective of this article is to report on the experiences in teaching, coming from the productive chain of sheep and goat meat, through an asynchronous meeting of the Research Group. The study is qualitative and descriptive, successful teaching practices of the subject Technology of Animal Products I, TPOA 1, are reported. However, the goat raising chain in Brazil is disorganized, there is a lack of standardization of the animals to be slaughtered and clandestinity is still highly regarded for this operation, in case if there is the consumption of these meats without sanitary inspection. Thus, the production chain of sheep and goat meat consists of the following steps: obtaining inputs; production; processing; distribution / consumption; and consumer. During the preparation of this article, reports of successful experiences in the processing link became evident. Due to the pandemic of the new Coronavirus, the report of teaching experience on the subject in question gained a new format, via remote activity, which allows the insertion of digital educational platforms, in order to maintain the interest and involvement of students.
\end{abstract}

\footnotetext{
1 Mestrado em Ciência e Tecnologia de Alimentos, pela Universidade Federal do Ceará (2005) e doutorado em Zootecnia, pela Universidade Federal de Viçosa (2017). Atualmente está professora do Instituto Federal do Ceará, campus Crato, curso Bacharelado em Zootecnia.

2 Mestrado em Ensino de Ciências e Matemática pela Universidade Luterana do Brasil (2008) e Doutora em Ciências Sociais - UNISINOS (2017)

${ }^{3}$ Doutora em História pela Universidade Vale do Rio dos Sinos - UNISINOS. Mestre em Ciências com ênfase em Educação Agrícola pela Universidade Federal Rural do Rio de Janeiro - UFRRJ (2011). Especialista em Metodologia do Ensino Fundamental e Médio pela Universidade Estadual Vale do Acaraú - UVA (2001)

${ }^{4}$ Mestre em Educação e Ensino pelo Mestrado Acadêmico Intercampi em Educação e Ensino - MAIE - da Universidade Estadual do Ceará - UECE. Professora do Instituto Federal de Educação, Ciência e Tecnologia do Ceará - IFCE, atuando na área de Fundamentos Sócio-filosóficos da Educação, Políticas Educacionais e Gestão Educacional.

5 Mestrado em Ciência Animal (com ênfase em Nutrição de Ruminantes), pelo Programa de Pós-graduação em Ciência Animal, da Universidade Federal do Vale do São Francisco - UNIVASF campus Ciências Agrárias.
} 


\title{
RECIMA21 - REVISTA CIENTÍFICA MULTIDISCIPLINAR
}

\author{
ENSINO DA CADEIA PRODUTIVA DA CARNE OVINA E CAPRINA: RELATO DE EXPERIÊNCIA DE UMA \\ PRÁTICA PEDAGÓGICA NO ENSINO REMOTO \\ Francisca Giselle da Cruz, Maria Aparecida Ferreira Barbosa Fernandes, Marcia Leyla de Freitas Macedo Felipe,
Daniela Glicea Oliveira da Silva, Priscila Izidro de Figueirêdo
}

KEYWORDS: Covid-19. Digital tools. Remote educational activity.

\section{INTRODUÇÃO}

O Brasil tem uma longa tradição de produção de ovinos e caprinos, principalmente no que tange a produção de lã e leite e, mais recentemente, de carne. Segundo os dados do IBGE (2017), no país há um rebanho ovino de mais de 18 milhões de cabeças e um rebanho caprino de 9 milhões. As regiões nordeste e sul se destacam pelo rebanho ovino, enquanto os caprinos se concentram na região nordeste do país.

A criação de ovinos e caprinos é uma prática realizada em diversas regiões do mundo, devido a capacidade de adaptação desses animais frente as mais variadas condições edafoclimáticas. De acordo com Ximenes e Cunha (2012), alguns países com baixos índices de alimentos e renda possuem elevado índices relativos à ovinocaprinocultura.

A ovinocaprinocultura no Brasil, de forma geral, pode ser caracterizada como uma atividade extensiva, com baixos níveis tecnológicos e baixos índices zootécnicos. A maioria dos abates são feitos de forma clandestina, gerando produtos sem padronização e certificação de qualidade. Estes fatores, como discorrem Sório e Rasi (2010), associados a irregularidade na oferta, representam grandes entraves à fidelização do consumidor, no que diz respeito aos diversos produtos oriundos deste agronegócio.

Segundo Silva (2002) é complexo delimitar a estrutura dos principais segmentos na cadeia produtiva da ovinocaprinocultura devido as especificidades, distribuição espacial de produção e, principalmente, por se tratar de duas espécies distintas, apesar de que os principais segmentos da cadeia estejam bem identificados. Segundo o mesmo autor, o produtor rural é o mais prejudicado dentro da cadeia produtiva, pois não existe incentivos para diferenciá-lo dos padrões da concorrência, sistemas de comercialização e formas de governança, principalmente porque não há informações e intermediação entre o produtor e os outros segmentos.

Entretanto, a cadeia produtiva da ovinocaprinocultura no Brasil é desarticulada, como apontam Carvalho e Souza (2008), pois não há oferta regular de produtos em quantidade e qualidade, além de não apresentar um padrão que satisfaça o mercado consumidor. Neste sentido, ressalta-se que o Congresso Nacional e o Presidente da República decretaram e sancionaram a Lei, de $\mathrm{n}^{\circ} 13.854^{1}$ de 09 de julho de 2019, que institui a Política Nacional de Incentivo à ovinocaprinocultura.

O Grupo de Pesquisa em Processamento de Produtos Agroalimentares (G-Proagro) desenvolve pesquisas em tecnologias de carnes e derivados, desde 2010. Neste âmbito, as seguintes problemáticas foram levantadas: Quais são os fatores que influenciam na cadeia produtiva da carne? Como as mídias digitais educacionais podem auxiliar na construção deste conhecimento?

\footnotetext{
1 Institui a Política Nacional de incentivo à ovinocaprinocultura.
} 


\section{RECIMA21 - REVISTA CIENTÍFICA MULTIDISCIPLINAR}

ENSINO DA CADEIA PRODUTIVA DA CARNE OVINA E CAPRINA: RELATO DE EXPERIÊNCIA DE UMA
PRÁTICA PEDAGÓGICA NO ENSINO REMOTO
Francisca Giselle da Cruz, Maria Aparecida Ferreira Barbosa Fernandes, Marcia Leyla de Freitas Macedo Felipe,
Daniela Glicea Oliveira da Silva, Priscila Izidro de Figueirêdo

Pesquisas conduzidas em cidades brasileiras trazem estimativas sobre o consumo per capita de carne ovina e caprina. Sório (2008) destaca que o consumo de carne ovina no país é considerável, mas ainda aquém do consumo de carne bovina. O Estado do Rio Grande do Sul é o que mais consome carne ovina, com um consumo de 2,90 kg/ano por habitante.

O consumo médio de carne caprina/pessoa/ano no Brasil ainda é considerado baixo, principalmente quando comparado com outros produtos cárneos existentes. Estudos realizados mostram resultados de consumo de 700 gramas/pessoa/ano para o Brasil, enquanto que o consumo em países do primeiro mundo varia de 20 a 28 kg/pessoa/ano. Segundo Pessoa (et al., 2019), esse panorama ocorre pela pouca disponibilidade e pela falta de qualidade do produto colocado à venda.

Quando se refere ao envolvimento da academia nesses processos, é fundamental considerar os fatores que podem beneficiar a sua efetividade. Deste modo, a internet e, consecutivamente, as mídias digitais, de acordo com Antunes (2012), podem ajudar na construção do conhecimento, sendo ferramentas fundamentais aos professores, que podem se reinventar e descobrir novas formas de aprendizagem.

Diante do exposto, o objetivo geral do presente trabalho foi relatar as vivências em docência, sobre a cadeia produtiva da carne ovina e caprina, em tempos de ensino remoto, devido a pandemia ocasionada pelo Novo Coronavírus (COVID-19). Os objetivos específicos foram: expor experiências oriundas da disciplina de Tecnologia de Produtos de Origem Animal I (do curso Bacharelado em Zootecnia do IFCE, campus Crato), por intermédio de uma reunião do Grupo de Pesquisa e enfatizar os novos aspectos da vivência docente, após inserção das plataformas educacionais digitais, para abordar assuntos que envolvem a cadeia produtiva da carne ovina e caprina.

\section{REFERENCIAL TEÓRICO}

\subsection{Importância de abordagens sobre a cadeia da carne ovina e caprina no curso de bacharelado em zootecnia}

A cadeia produtiva, segundo definição de Davis e Goldberg (1957 apud ARAÚJO NETO; COSTA, 2005), é o total das operações de produção; distribuição de suprimentos agrícolas; das operações de produção na propriedade; do armazenamento; processamento; e distribuição dos produtos resultantes da atividade. Para o bom funcionamento desta cadeia produtiva é importante que informações do mercado e dos segmentos sejam consideradas na propriedade, pois isso aumenta a eficiência de todos os elos produtivos. Carvalho e Souza (2008) afirmam que a cadeia produtiva deve ser observada como um conjunto de segmentos responsáveis por determinadas fases do processo, onde todas contribuem para o desenvolvimento do produto final, sem que haja uma individualidade entre estes agentes.

Para o bom desenvolvimento da cadeia produtiva da ovinocaprinocultura de corte e para o solucionamento dos problemas acima citados, é importante trabalho e esforço conjunto de todos os segmentos da cadeia envolvidos no processo. De acordo com Rosanova (2004), com o mercado 


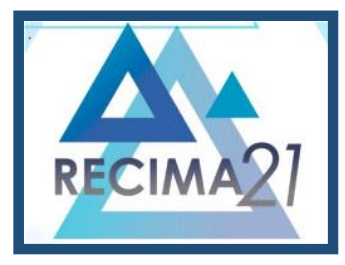

\title{
RECIMA21 - REVISTA CIENTÍFICA MULTIDISCIPLINAR
}

\author{
ENSINO DA CADEIA PRODUTIVA DA CARNE OVINA E CAPRINA: RELATO DE EXPERIÊNCIA DE UMA \\ PRÁTICA PEDAGÓGICA NO ENSINO REMOTO \\ Francisca Giselle da Cruz, Maria Aparecida Ferreira Barbosa Fernandes, Marcia Leyla de Freitas Macedo Felipe,
Daniela Glicea Oliveira da Silva, Priscila Izidro de Figueirêdo
}

mais exigente e globalizado, prevalecerá o desenvolvimento de projetos cooperativos e a interação entre os órgãos governamentais, logo a iniciativa privada terá que ser permanente e crescente.

A ovinocaprinocultura é uma atividade econômica explorada em todos os continentes, estando presente em áreas que apresentam as mais diversas características edafoclimáticas. No entanto, somente em alguns países essa atividade apresenta expressão econômica, sendo, na maioria dos casos, desenvolvida de forma empírica e extensiva, adotando baixos níveis de tecnologia e, consequentemente, apresentando baixa produtividade e reduzida rentabilidade, como discorrem Nogueira Filho e Alves (2002).

No que tange aos pressupostos Legais, quanto a Lei de Diretrizes e Bases da Educação Nacional (LDB) Lei 9.394² de 1996 (BRASIL, 1996), o curso de Bacharelado em Zootecnia está fundamentado no Art. 39, que dispõe sobre a Educação Profissional e Tecnológica, e nos Art. 43 a 57, que tratam sobre as finalidades, abrangência e organização do Ensino Superior.

A Zootecnia, enquanto ciência, está voltada à "criação racional de animais domésticos, silvestres e em domesticação", explorando-os de maneira econômica, visando conduzir suas atividades sempre dentro de princípios que pautem o bem-estar animal, equilíbrio ambiental e sustentável da biodiversidade. Segundo Diamond (2002), as atividades inerentes a esta ciência datam de tempos remotos, desde a iniciativa do homem em domesticar os animais com a finalidade de se obter força de tração, vestimenta, alimento e proteção.

A Resolução $n^{\circ} 007^{3}$, de 10 de março de 2010 aprova ad referendum do CONSUP, do IFCE, dispondo sobre a criação do curso superior de Bacharelado em Zootecnia do IFCE campus Crato. Contudo, a Resolução № 6194 , de 14 de dezembro de 1994 (BRASIL, 1994), especifica o campo de atividades do Zootecnista, sendo que a Lei oㅜ $5.550^{5}$, de 04 de dezembro de 1968 (BRASIL, 1968), dispõe sobre o exercício da profissão de Zootecnista. Nos cursos do eixo de Recursos Naturais constantes no Parecer pela Câmara de Educação Superior (CES), do Conselho Nacional de Educação (CNE), n $337^{6}$ de 2004 (BRASIL, 2004), sobre as Diretrizes de Curriculares Nacionais (DCNs), encontra-se o curso Bacharelado em Zootecnia, sendo que a disciplina de Tecnologia de Produtos de Origem Animal I - TPOA 1, compõe o eixo de formação específica. Sendo assim, as

2 O curso de Bacharelado em Zootecnia está fundamentado no Art. 39, que dispõe sobre a Educação Profissional e Tecnológica e nos Art. 43 a 57, que trata sobre as finalidades abrangência e organização do Ensino Superior. 1996.

3 Aprova ad referendum do Conselho Superior - CONSUP, do Instituto Federal de Educação, Ciência e Tecnologia - IFCE, a criação do curso superior de Bacharelado em Zootecnia e Sistema de informações do campus Crato.

${ }^{4}$ Especifica o campo de atividades do Zootecnista.

5 Dispõe sobre o exercício da profissão de Zootecnista.

6 Parecer pela Câmara de Educação Superior - CES do Conselho Nacional de Educação sobre as Diretrizes Curriculares Nacionais, encontra-se o curso Bacharelado em Zootecnia. 2004. 


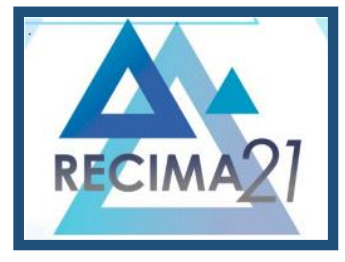

\title{
RECIMA21 - REVISTA CIENTÍFICA MULTIDISCIPLINAR
}

\author{
ENSINO DA CADEIA PRODUTIVA DA CARNE OVINA E CAPRINA: RELATO DE EXPERIÊNCIA DE UMA \\ PRÁTICA PEDAGÓGICA NO ENSINO REMOTO \\ Francisca Giselle da Cruz, Maria Aparecida Ferreira Barbosa Fernandes, Marcia Leyla de Freitas Macedo Felipe, \\ Daniela Glicea Oliveira da Silva, Priscila Izidro de Figueirêdo
}

atividades que podem ser exercidas pelo Zootecnista são descritas abaixo, conforme consta na Resolução CNE/CES ํo $04^{7}$, de 02 de fevereiro de 2006:

i) avaliar, classificar e tipificar produtos e subprodutos de origem animal, em todos os seus estágios de produção;

I) desenvolver pesquisas que melhorem as técnicas de criação, transporte, manipulação e abate, visando ao bem-estar animal e ao desenvolvimento de produtos de origem animal, buscando qualidade, segurança alimentar e economia; p) planejar, gerenciar ou assistir diferentes sistemas de produção animal e estabelecimentos agroindustriais, inseridos desde o contexto de mercados regionais até grandes mercados internacionalizados, agregando valores e otimizando a utilização dos recursos potencialmente disponíveis e tecnologias sociais e economicamente adaptáveis;

q) atender às demandas da sociedade quanto à excelência na qualidade e segurança dos produtos de origem animal, promovendo o bem-estar, a qualidade de vida e a saúde pública. (BRASIL, 2006)

Desse modo, vale ressaltar que as atribuições supracitadas são algumas das principais competências e habilidades da referida Resolução, sendo estas correlacionadas com a disciplina de TPOA 1, referente à cadeia produtiva da carne e a atuação do Zootecnista nesta tão importante área.

\subsection{Grupos de pesquisa e das vivências docentes no fortalecimento da cadeia da carne ovina e caprina}

O Conselho Nacional de Desenvolvimento Científico e Tecnológico (CNPq, 2010) define grupo de pesquisa como um conjunto de pesquisadores, docentes, estudantes e pessoal de apoio técnico, os quais podem se organizar em torno de linhas de pesquisas, as quais representam temas aglutinadores de estudos científicos, embasadas em orientações teóricas e metodológicas que determinam o rumo da investigação em um dado contexto ou realidade, de onde se originam projetos cujos resultados mantêm afinidades entre si.

Carneiro e Lourenço (2003) definem os grupos de pesquisa do CNPq da seguinte forma:

O Diretório dos Grupos de Pesquisa do CNPq reúne informações sobre os grupos de pesquisa em atividade no País abrangendo pesquisadores, estudantes, técnicos, linhas de pesquisa em andamento, produção científica, tecnológica e artística geradas pelos grupos. Apesar de ser caracterizado por uma base de informações de preenchimento opcional, o universo abrangido pela mesma vem aumentando ao longo do tempo, podendo-se supor ter relativa representatividade da comunidade científica nacional. (CARNEIRO; LOURENÇO, 2003)

Analisando a Resolução $n^{\circ} 29^{8}$, de 08 de agosto de 2014, do CONSUP/IFCE, que aprova o regulamento de criação, certificação, avaliação e descredenciamento de grupos de pesquisa do IFCE (2014), em seu Art. $2^{\circ}$, da referida Resolução, define-se Grupo de Pesquisa como um conjunto de pesquisadores organizados em torno de uma ou duas lideranças:

\footnotetext{
${ }^{7}$ Aprova as Diretrizes Curriculares Nacionais para o curso de graduação em Zootecnia e dá outrasprovidências. 2006

8 Aprova o regulamento de criação, certificação, avaliação e descredenciamento de grupos de pesquisa do IFCE.
} 


\title{
RECIMA21 - REVISTA CIENTÍFICA MULTIDISCIPLINAR
}

\author{
ENSINO DA CADEIA PRODUTIVA DA CARNE OVINA E CAPRINA: RELATO DE EXPERIÊNCIA DE UMA \\ PRÁTICA PEDAGÓGICA NO ENSINO REMOTO \\ Francisca Giselle da Cruz, Maria Aparecida Ferreira Barbosa Fernandes, Marcia Leyla de Freitas Macedo Felipe, \\ Daniela Glicea Oliveira da Silva, Priscila Izidro de Figueirêdo
}

Cujo fundamento organizador é a experiência, o destaque e a liderança no terreno cientifico, tecnológico e/ou de inovação;

No qual existe envolvimento profissional e permanente com a atividade de pesquisae inovação;

II. Cujo trabalho se organiza em torno de linhas comuns de pesquisa;

IV. Que, em algum grau, compartilha instalações e equipamentos. (IFCE, 2014)

No que diz respeito ao ensino em si, Freire (1997) afirma que "ensinar não é transferir conhecimento, mas criar as possibilidades para sua produção ou a sua construção" (FREIRE, 1997, p.27). Para a construção do conhecimento, o autor realça a importância da pesquisa, "não há ensino sem pesquisa e pesquisa sem ensino" (FREIRE, 1997, p.16). Em suas palavras há a afirmativa de que o docente continue buscando, procurando, a fim de que consiga constatar, intervir, educando-se para educar. A pesquisa permite conhecer o desconhecido e comunicar ou anunciar a novidade.

A Resolução $n^{\circ} 67^{9}$, de 31 de julho de 2017, aprova o Plano Estratégico Institucional de Permanência e Êxito dos Estudantes do Instituto Federal do Ceará. Nesse sentido, é relevante o reforço de ações que provoquem a participação dos estudantes em atividades de ensino, pesquisa e extensão, possibilitando aos estudantes um percurso exitoso de formação acadêmica e profissional, no sentido de garantir reais condições de permanência.

A Docência é exercida pelo professor, também chamado docente, palavra que vem do latim "docere", que significa ensinar e tem sua raiz de origem grega, "docxa", que significa verdade. $O$ docente pode ser considerado, também, aquele que tem uma doutrina, um espaço, uma visão e uma bagagem própria para transmitir via ensino. Segundo Rossato (2002), o docente é aquele que precisa produzir conhecimento novo sobre o que já domina, de modo a ter algo novo para ensinar, com capacidade de autonomia, sem apenas repetir o que o outro o ensinou.

Penteado (1988) compreende a Prática de Ensino como um "conjunto de condutas e procedimentos pedagógicos, vivenciados e experienciados dentro das instituições escolares" (PENTEADO, 1988, p.08). Segundo Gil (2008), os papéis que o docente exerce são numerosos e diversificados. Em sua obra, o autor reúne e descreve vinte e sete papéis, alguns deles são: o de administrador (quanto ao planejamento, organização, coordenação e avaliação do processo ensino- aprendizagem); o de especialista (devido a especialidade em um campo de conhecimento que o professor universitário necessita); o de aprendiz (para que seus conhecimentos mantenham-se atualizados); o de membro de equipe (diante do envolvimento com seus pares); o departicipante (já que o professor participa do processo de ensino aprendizagem); o de didata (que compreende a arte de ensinar); o de agente de socialização (por proporcionar aos alunos o aprendizado de valores sociais); entre outros.

9 Aprova o Plano Estratégico Institucional de Permanência e Êxito dos Estudantes do Instituto Federal do Ceará.2017. 


\section{RECIMA21 - REVISTA CIENTÍFICA MULTIDISCIPLINAR}

ENSINO DA CADEIA PRODUTIVA DA CARNE OVINA E CAPRINA: RELATO DE EXPERIENNCIA DE UMA
PRÁTICA PEDAGÓGICA NO ENSINO REMOTO
Francisca Giselle da Cruz, Maria Aparecida Ferreira Barbosa Fernandes, Marcia Leyla de Freitas Macedo Felipe,
Daniela Glicea Oliveira da Silva, Priscila Izidro de Figueirêdo

Ainda segundo o mesmo autor, diante dessa diversidade de papéis nota-se a amplitude em termos da formação desse profissional face às suas demandas cotidianas. Alguns desses papéis necessitam de habilidades e competências que vão além do conhecimento específico previsto na disciplina ministrada, como Gil (2008) discorre, denotando maior interação entre a teoriae a prática do exercício profissional.

De acordo com Freire (1996), o primeiro passo para uma boa formação do docente é a consciência de que ensinar não é transmitir conhecimento, mas construir possibilidades para a sua produção ou construção. Para o autor, o educador deve estar consciente da necessidade de sua constante formação, assim como o educando, visto que esse processo é consequência da relação entre os dois agentes. Pensar sobre o importante papel que o docente exerce na formação do discente leva a analisar a importância da qualificação destes profissionais. Desse modo, com base em Caldeira e Zaidan (2010), existem alguns aspectos que são marcantes em relação às particularidades do professor, no contexto da prática pedagógica: "sua experiência, sua corporeidade, sua formação, condições de trabalho e escolhas profissionais" (CALDEIRA; ZAIDAN, 2010, p. 21).

Conforme Franco (2016), apenas ação a docente, quando realizada como prática social, é capaz de "produzir saberes, saberes disciplinares, saberes referentes a conteúdos e sua abrangência social, ou mesmo saberes didáticos, referentes às diferentes formas de gestão de conteúdos, de dinâmicas da aprendizagem, de valores e projetos de ensino" (FRANCO, 2016, p. 545).

1.3 Desafios da pandemia do novo coronavírus no contexto do ensino e alternativas promissoras

O ano de 2020 ficará marcado em nossa história por uma pandemia provocada pelo novo coronavírus (SARS-CoV-2), que se alastrou e vem matando milhares de pessoas pelo mundo. Trata-se de um vírus que provoca uma doença respiratória aguda que pode levar ao óbito. $\mathrm{O}$ cenário que se desenha diante dessa pandemia é de incertezas, inseguranças e adaptações em todasas dimensões sociais, como na saúde; na política; na economia; e na educação. No Brasil, como discrevem Goedert e Arndt (2020), o anúncio da pandemia aconteceu no mês de março de 2020 e veio acompanhado de medidas de restrição social (quarentena), exigindo ajustamentos dos vários setores da sociedade, dentre eles o da Educação, que, pelas suas especificidades, foi um dos primeiros a ter suas atividades interrompidas.

Seguindo essa linha, o Ministério da Educação e Cultura - MEC (BRASIL, 2020b) publicou a Portaria $n^{\circ} 343^{10}$ de 17 de março de 2020 , que dispõe sobre a substituição das aulas presenciais por aulas e meios digitais enquanto durar a situação de pandemia do Novo Coronavírus COVID-19. Contudo, o surto da doença decretou uma emergência na saúde pública mundial, poresta razão nos encontramos em isolamento social. Neste sentido, são necessárias precauções para impedir a

10 Dispõe sobre a substituição das aulas presenciais por aulas em meios digitais e enquanto durar a situação de pandemia do Novo Coronavírus - COVID-19. 
propagação da COVID-19. Logo, o IFCE adotou como estratégia a formação do Comitê de Enfrentamento ao Novo Coronavírus (CEC/IFCE), instituído pela Portaria 꾸18/GABR/Reitoria ${ }^{11}$, de 16 de março de 2020, com o objetivo de gerenciar as propostas de mitigação idealizadas pelas próreitorias, pelas diretorias sistêmicas e pelos 33 campi.

Posteriormente, o MEC estendeu a autorização de aulas remotas até 31 de dezembro de 2020, em substituição às aulas presenciais e publicou no Diário Oficial da União - D.O.U., a Portaria de oㅡ $544^{12}$, de 16 de junho de 2020 (BRASIL, 2020a), que autoriza a utilização de meios e tecnologias digitais para a substituição temporária das aulas presenciais em IES enquanto durar a situação de pandemia de COVID-19.

Nesse sentido, após a pandemia, possivelmente, o rico aprendizado adquirido em um período tão curto e peculiar respaldará à implementação de tecnologias digitais no cenário mundial, pois foi possível vislumbrar o ensino mediado por tecnologia como uma ferramenta adicional ao processo ensino aprendizagem. Assim, nos diferentes períodos do curso, essa necessidade emergencial de mudança e adaptação foi percebida e valorizada, tanto pelos docentescomo pelos estudantes, em consonância com a complexidade e particularidade de cada período. Os desafios e a ressignificação são constantes no dia a dia dos docentes e estudantes nesse momento de pandemia, como lembra Regueiro (et al., 2020), sendo superados e vividos na esperade um futuro no qual a resiliência fará parte da história.

As ferramentas de comunicação em meio digital são muitas, e cada escola adotou estratégias de acordo com seus objetivos educacionais. Dentre os meios que estão sendo mais utilizados, de acordo com Machado (2020), estão: Google Classroom; o aplicativo "Zoom"; "Youtube"; grupos de "WhatsApp"; dentre outros. É possível observar que, diante do contexto de ensino remoto, os docentes tiveram que replanejar os métodos de ensino, o que culminou em uma perspectiva de inovação pedagógica que já vinha ocorrendo, mas que, em função da situação atual de pandemia, foi acelerada abruptamente para atender à necessidade de adaptações imediatas, como ressalta Regueiro (et al., 2020).

\section{METODOLOGIA}

O presente estudo é de natureza qualitativa e descritiva, seguindo a proposta de Marconi e Lakatos (2013). Vale elucidar que esta pesquisa foi fundamentada em duas principais etapas: a elaboração do relato das vivências e a exposição/apresentação desse relato em tempos de pandemia, sendo diferenciada a coleta de dados conforme cada etapa.

\footnotetext{
11 Art. 1ำ Fica instituído o Comitê de Enfrentamento (CEC/IFCE) ao novo Coronavírus (COVID-19), com o objetivo de gerenciar as questões inerentes aos impactos decorrentes do COVID-19, no âmbito do IFCE. 2020. 12 Dispõe sobre a substituição das aulas presenciais por aulas em meios digitais, enquanto durar a situação de pandemia do novo coronavírus - Covid-19, e revoga as Portarias MEC nํ 343, de 17 de março de 2020a, nํ345, de 19 de março de 2020, e no 473, de 12 de maio de 2020.
} 


\section{RECIMA21 - REVISTA CIENTÍFICA MULTIDISCIPLINAR}

ENSINO DA CADEIA PRODUTIVA DA CARNE OVINA E CAPRINA: RELATO DE EXPERIÊNCIA DE UMA PRÁTICA PEDAGÓGICA NO ENSINO REMOTO Francisca Giselle da Cruz, Maria Aparecida Ferreira Barbosa Fernandes, Marcia Leyla de Freitas Macedo Felipe,

Daniela Glicea Oliveira da Silva, Priscila Izidro de Figueirêdo

\subsection{Elaboração do relato das vivências}

Inicialmente, elaborou-se um relato das vivências da docente responsável pela disciplina de TPOA 1 sobre a cadeia da carne ovina e caprina. Para tanto, a coleta de dados foi do tipo documentação indireta, seguindo a técnica de pesquisa documental de fonte primária, que, conforme Marconi e Lakatos (2013, p. 43-44), baseia-se restritamente a documentos (como diários, autobiografias, relatos de visitas ou de viagens), sejam eles escritos ou não, contemporâneos ou restrospectivos. Dessa forma, com base nestes registros pessoais (textos e imagens), foi planejada e elaborada uma apresentação, utilizando a ferramenta do PowerPoint(do pacote da Microsoft Office para Windows $\AA_{10}$ ), para ser aplicada na etapa seguinte.

\subsection{Exposição remota do relato}

A segunda etapa constituiu-se na exposição destas vivências para um público específico, a comunidade interna e externa do IFCE campus Crato. Para contemplar a proposta, foram criadas duas plataformas digitais (redes sociais) sobre a qualidade e ciência da carne, a fim de tornar a atividade remota mais dinâmica e criativa, além de incentivar a leitura e a atualização da temática deste estudo, utilizados como recurso para mediação do processo de aprendizagem em tempos de pandemia. Por meio das redes sociais, foi divulgado um convite para uma reunião, que constituiu a apresentação do relato das vivências. Desse modo, no dia 20 de junho de 2020, às quinze horas, a reunião foi realizada de forma síncrona, apresentada aos usuários por videoconferência, via Google Meet.

A coleta e análise de dados, pertinentes à proposta do estudo, foram realizadas após vídeoconferência. Assim, a coleta de dados nesta etapa baseou-se na documentação direta, seguindo a técnica da observação individual (por apenas um pesquisador) que, segundo Marconi e Lakatos (2013, p.79), tem a sua personalidade projetada sobre o observado: os eventos reais e as suas interpretações. Neste trabalho, a observação consistiu na percepção dopesquisador sobre a sua experiência de expor suas vivências, de forma remota, refletindo sobre as contribuições destes momentos em tempos de pandemia. 


\section{RECIMA21 - REVISTA CIENTÍFICA MULTIDISCIPLINAR}

ENSINO DA CADEIA PRODUTIVA DA CARNE OVINA E CAPRINA: RELATO DE EXPERIÊNCIA DE UMA PRÁTICA PEDAGÓGICA NO ENSINO REMOTO

Francisca Giselle da Cruz, Maria Aparecida Ferreira Barbosa Fernandes, Marcia Leyla de Freitas Macedo Felipe,
Daniela Glicea Oliveira da Silva, Priscila Izidro de Figueirêdo

Em síntese, o percurso metodológico aplicado está representado abaixo, na Figura 1.

Figura 1 - Percurso metodológico.

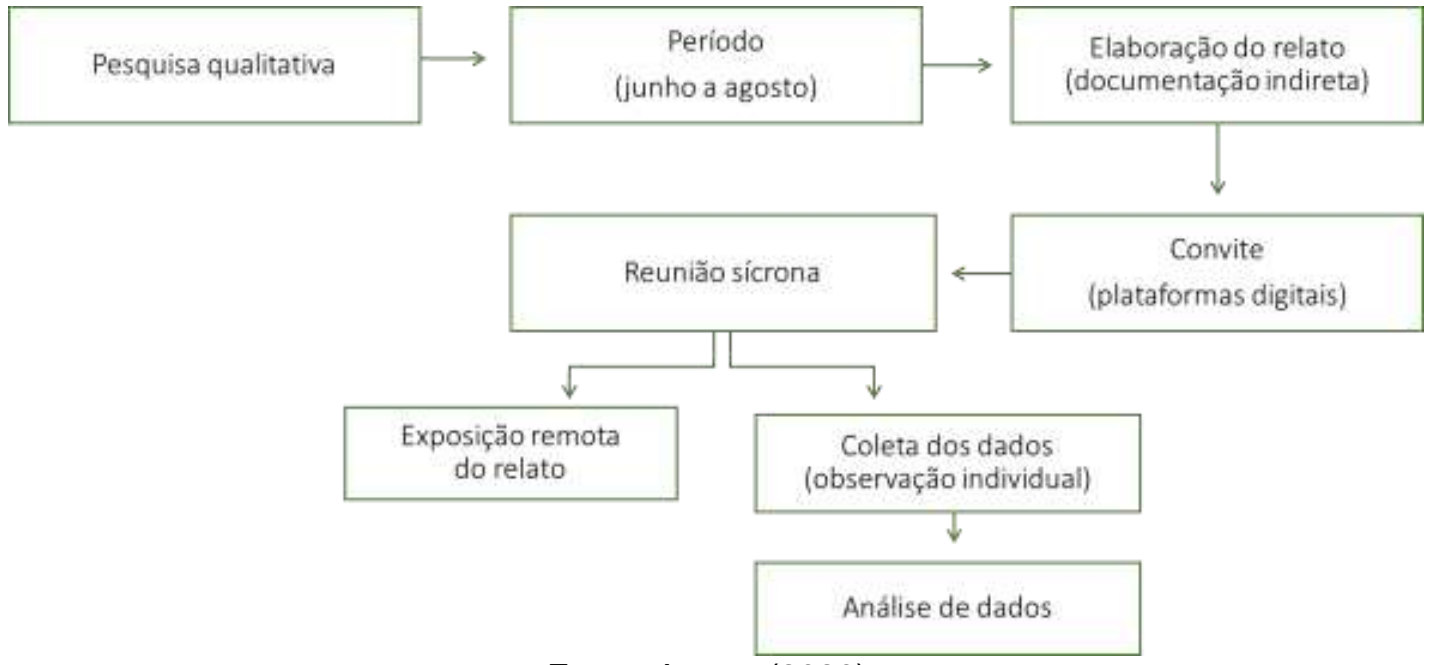

Fonte: Autora (2020).

\section{RESULTADOS E DISCUSSÃO}

$\mathrm{Na}$ concepção deste trabalho, estudos sobre a cadeia produtiva da carne ovina e caprina possibilitaram aos acadêmicos do curso Bacharelado em Zootecnia e público externo a compreenção sobre a cadeia produtiva da carne ovina e caprina, desde a obtenção de insumos; produção; processamento; distribuição; e consumo e consumidor, segundo International Fund for Agricultural Development (Fundo Internacional de Desenvolvimento Agrário) - IFAD (2010).

A Figura 2 apresenta as práticas das vivências em docência na disciplina de TPOA 1, do curso Bacharelado em Zootecnia do IFCE campus Crato, em destaque a um dos elos da cadeia produtiva da carne, o processamento da carne ovina e caprina por meio da elaboração de seus derivados. As práticas realizadas a partir da carne ovina foram: hambúrguer de carne ovina, kafta, buchada e a manta, além da obtenção dos cortes cárneos nobres (ex: carré francês e desossa da perna), já para carne caprina, o processamento de salame tipo Italiano e linguiça artesanal, de forma a incentivar o consumo efetivo destes produtos, considerado baixo no Brasil, em média $700 \mathrm{~g} / \mathrm{habitante} / \mathrm{ano}$.

A disciplina de TPOA 1 prende a atenção dos alunos, por suas práticas em tecnologia de carnes e derivados. Relatar estas experiências ao público interno e externo do IFCE foi uma experiência bastante interessante e enriquecedora, de forma a divulgar que é possivel consumir não só a carne de ovina e caprina in natura, mas também os seus derivados, de fácil preparo.

Figura 2 - Vivências em docência na cadeia produtiva da carne ovina e caprina. 


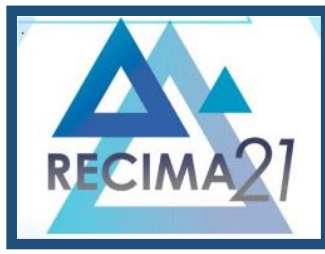

\section{RECIMA21 - REVISTA CIENTÍFICA MULTIDISCIPLINAR}

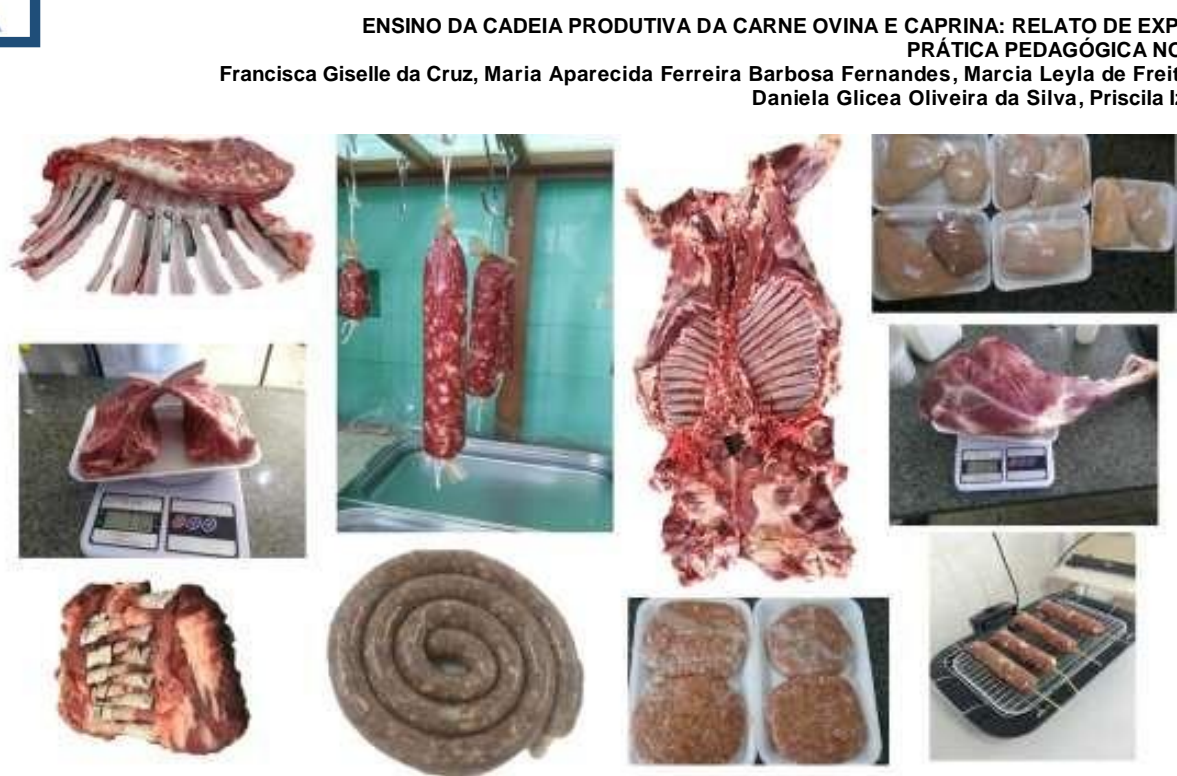

Fonte: Autora (2020).

Segundo Sousa (2007) é interessante representar uma cadeia produtiva a partir dos seus vários 'segmentos'. Nesse contexto, é importante elucidar o que constitui a cadeia produtiva da carne ovina e caprina, como mostra a Figura 3.

Figura 3 - Cadeia produtiva da carne ovina e caprina.

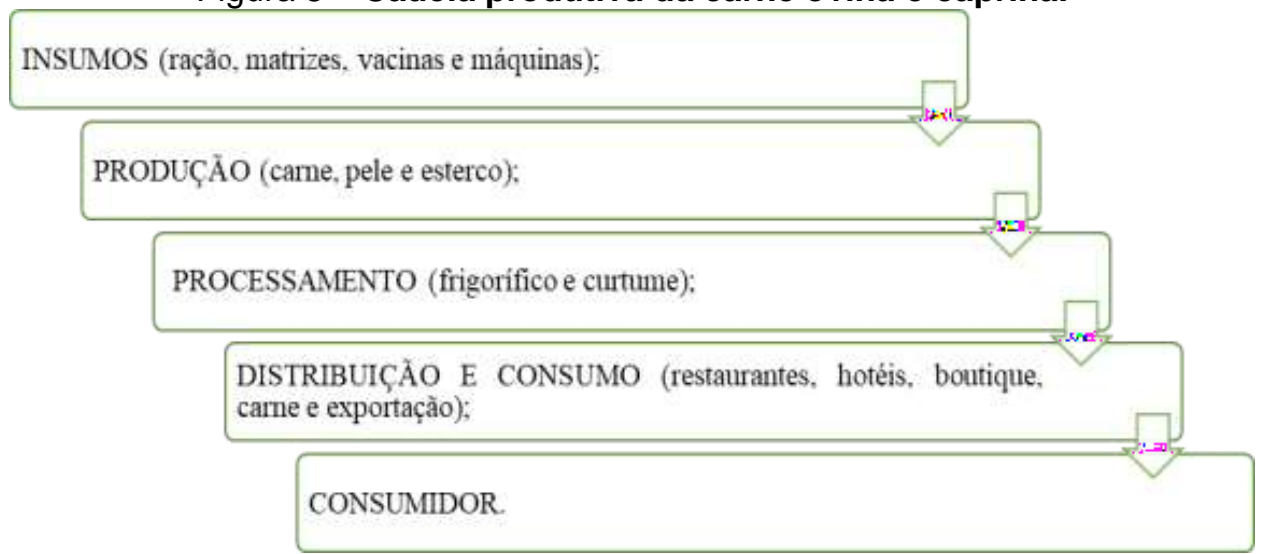

Fonte: Adaptado de IFAD, 2010 (2020).

Para Prochnik (2013), a ideia de cadeia produtiva tem origem na crescente divisão do trabalho e na interdependência cada vez maior entre os agentes econômicos, o conceito tem se tornado uma ferramenta de uso cada vez mais frequente em estudos socioeconômicos. Contudo, compreender cada elo da cadeia da carne faz-se importante a fim de calcular os custos de produção, impostos, fluxo de caixa e obtenção do produto final com qualidade higiênico-sanitáriae segurança alimentar.

Uma publicação do IFAD (2010) fornece a seguinte definição para o conceito de cadeia produtiva ou cadeia de valor: é o conjunto de processos pelo qual passa um produto, partindo desde 


\title{
RECIMA21 - REVISTA CIENTÍFICA MULTIDISCIPLINAR
}

\author{
ENSINO DA CADEIA PRODUTIVA DA CARNE OVINA E CAPRINA: RELATO DE EXPERIÊNCIA DE UMA \\ PRÁTICA PEDAGÓGICA NO ENSINO REMOTO \\ Francisca Giselle da Cruz, Maria Aparecida Ferreira Barbosa Fernandes, Marcia Leyla de Freitas Macedo Felipe, \\ Daniela Glicea Oliveira da Silva, Priscila Izidro de Figueirêdo
}

o produtor primário até chegar ao consumidor final. Em princípio, agrega-se valor em cada etapa da cadeia, assim surge o termo "cadeia de valor".

A Figura 4 apresenta os tópicos dos relatos durante a reunião virtual. Os termos técnicos foram explicados, para que a comunidade acadêmica interna e externa compreendesse a importância dos mesmos. A apresentação foi proferida em PowerPoint.

Figura 4 - Tópicos discutidos sobre as vivências docente inerente à cadeia produtiva da carne ovina e caprina.

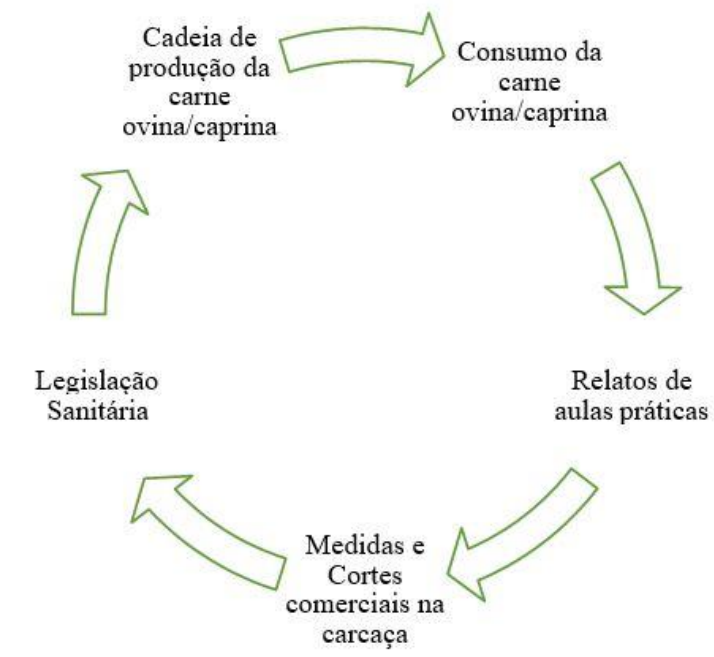

Fonte: Autora (2020).

Segundo Dias e Leite (2010), estudos mostram que "o sucesso de um curso depende também do tipo de mídia e tecnologia e de como elas são utilizadas" (DIAS; LEITE, 2010, p. 83), por isso a importância de o educador conhecer seu aluno e planejar todo o conteúdo considerando mídias, tecnologias, formas de acesso, familiaridade com o "ciberespaço". Por esta razão, um treinamento sobre ferramentas digitais educacionais foi proferido aos docentes do IFCE campus Crato, treinamento este que auxiliou na confecção e transmissão das vivências emdocência de modo remoto.

De acordo com a visão de Lima (2011), as redes sociais virtuais são grupos ou espaços específicos na internet, que permitem partilhar dados e informações, sendo estas de caráter geral ou específico, das mais diversas formas (textos, arquivos, imagens/fotos, vídeos e links). Logo, podem contribuir também para a implementação de práticas pedagógicas multidisciplinares, diversificadas, que superem a concepção da ciência e tecnologia como um instrumento, de forma a contribuir para uma educação mais efetiva e criativa.

Vale ressaltar que a plataforma digital é uma ação de extensão, cujo o objetivo é levar conhecimento técnico-científico para a comunidade acadêmica, produtores, profissionais e egressos, por meio de assuntos regulatórios para produtos de origem animal, diário de bordo das aulas e 


\title{
RECIMA21 - REVISTA CIENTÍFICA MULTIDISCIPLINAR
}

\author{
ENSINO DA CADEIA PRODUTIVA DA CARNE OVINA E CAPRINA: RELATO DE EXPERIÊNCIA DE UMA \\ PRÁTICA PEDAGÓGICA NO ENSINO REMOTO \\ Francisca Giselle da Cruz, Maria Aparecida Ferreira Barbosa Fernandes, Marcia Leyla de Freitas Macedo Felipe,
Daniela Glicea Oliveira da Silva, Priscila Izidro de Figueirêdo
}

assuntos relacionados à ciência da carne e divulgação de eventos em mídias digitais, destinados para público interno e externo do IFCE, caracterizada como uma atividade de prática docente.

Como perspectiva futura pretende-se estudar análise sensorial de cortes nobres e não de carne ovina e caprina, assim como o perfil do consumidor da região do Cariri cearense, por meio de submissão de projetos de pesquisa e extensão do IFCE.

As ferramentas digitais de forma síncrona (em tempo real) e assíncrona (quando alunos, professores e colegas podem efetuar a comunicação em tempos distintos, como blogs ou mural virtual), como discorre Haguenauer (et al., 2010, p. 32), têm sido grandes e bons aliados em tempos de ensino remoto emergencial. Desse modo, corroboramos com Hodges (et al., 2020), quando afirmam que a educação remota online digital se diferencia da Educação a Distância (EaD) pelo caráter emergencial, que propõe usos e apropriações das tecnologias em circunstâncias específicas de atendimento onde outrora existia regularmente a educação presencial.

Nesse sentido, a proposta deste estudo em repassar essas informações por meio de reunião online foi efetiva, envolvendo públicos-alvo interno e externo às atividades acadêmicas do IFCE campus Crato. Na ocasião observou-se que a plataforma utilizada para a transmisão favoreceu a apresentação do conteúdo, além de tornar os discentes mais participativos e interessados, tornando a reunião ainda mais instigante, colaborativa, significativa, motivacionale atraente. E em relação ao momento atualmente vivenciado, em que os encontros presenciais são restritos, os participantes consideraram cruciais reuniões virtuais para discutir assuntos, tanto sobre a cadeia produtiva da carne ovina e caprina, como as vivências docentes que envolvem esta cadeia, a fim de contribuir com seu fortalecimento. Assim, aderir as mídias educacionais digitais em tempos de isolamento social e ensino remoto, devido a pandemia ocasionada pelo Covid-19 foi bastante produtiva e contemplou os objetivos propostos.

Com isto, pode-se afirmar que a socialização e a troca dos conhecimentos colaboram para um movimento de contribuição para a vida profissional dos discentes e público externo, com o planejamento de atividades e com a reflexão na forma de registros que permitem a mobilização de saberes disciplinares, curriculares e pedagógicos, conforme destaca Tardif (2002), os quais podem fundamentar a formação do futuro profissional e contribuir significativamente na constituição de seus saberes.

\section{GERAÇÃO E RECOMENDAÇÕES}

Devido a pandemia do novo Coronavírus, o relato de vivência em docência da cadeia produtiva da carne ovina e caprina ganhou um novo formato, por intermédio de atividade remota,que possibilita a inserção das plataformas educacionais digitais, de forma a manter 0 interesse e 0 envolvimento dos discentes. Dessa forma, esta pode ser uma prática pedagógica aplicável a qualquer área de conhecimento. A metodologia aplicada, via atividade remota, motivou os estudantes 


\title{
RECIMA21 - REVISTA CIENTÍFICA MULTIDISCIPLINAR
}

\author{
ENSINO DA CADEIA PRODUTIVA DA CARNE OVINA E CAPRINA: RELATO DE EXPERIÊNCIA DE UMA \\ PRÁTICA PEDAGÓGICA NO ENSINO REMOTO \\ Francisca Giselle da Cruz, Maria Aparecida Ferreira Barbosa Fernandes, Marcia Leyla de Freitas Macedo Felipe, \\ Daniela Glicea Oliveira da Silva, Priscila Izidro de Figueirêdo
}

a dialogarem sobre o assunto em questão de forma mais dinâmica e participativa, por meio de uma postura crítica e interativa.

\section{REFERÊNCIAS BIBLIOGRÁFICAS}

ANTUNES, V. A Cultura tecnológica e a escola. Rio de Janeiro: Farias Brito, 2012. Disponívelem: http://www.fariabrito.com.br. Acesso em: 22 set 2020.

ARAÚJO NETO, D. L; COSTA, E. de F. Dimensionamento do PIB do agronegócio em Pernambuco.

Revista de Economia e Sociologia Rural, Brasília, v. 43, n. 4, p. 725-757, out./dez. 2005.

Disponível em: http://www.scielo.br/pdf/resr/v43n4/27753.pdf. Acesso em:10 out. 2020.

BRASIL. CNE n 337 de 2004. Brasília: Atos do Poder Legislativo, 2004.

BRASIL. Lei de Diretrizes e Bases da Educação Nacional 9.394 de 1996. Brasília: Casa Civil, 1996.

BRASIL. Lei $\mathbf{n}^{\circ}$ 13.854, de 8 de junho de 2019. Disponível em: https://www.in.gov.br/web/dou//lei-n13.854-de-8-de-julho-de-2019-190108032. Acesso em: 22 de jun. 2020.

BRASIL. Lei no 5.550 de 04 de dezembro de 1968. Brasília: Casa Civil, 1968.

BRASIL. Portaria n544, de 16 de junho de 2020. 2020a. Disponível em: www.in.gov.br/en/web/dou/-/portaria-n-544-de-16-de-junho-de-2020-261924872. Acesso em: 22 jun. 2020.

BRASIL. Resolução CNE/CES № 4, de 2 de fevereiro de 2006. Brasília: Ministério da Educação, 2006.

BRASIL. Portaria no 343, de 17 de março de 2020. Diário Oficial da União, Brasília, DF,18 mar. 2020b. Ed. 53. Seção 1, p. 39. 2020b. Disponível em: http://www.in.gov.br/web/dou/-/portaria- n-343de-17-de-marco-de-2020-248564376. Acesso em: 23 jun. 2020.

BRASIL. Resolução no 619, de 14 de Dezembro de 1994. Brasilia: CFMV, 1994.

CALDEIRA, A. M. S.; ZAIDAN, S. Prática pedagógica. In.: OLIVEIRA, D. A.; DUARTE, A. C.; VIEIRA, L. M. F. (Org.). Dicionário: trabalho, profissão e condição docente. Belo Horizonte: UFMG, 2010.

CARNEIRO, S. J.; LOURENÇO, R. Pós-graduação e pesquisa na universidade. In.: VIOTTI, E. B.; MACEDO, M. (Orgs.). Indicadores de ciência, tecnologia e inovação no Brasil. Campinas: Editora da Unicamp, 2003. Cap. 4. p.169-227.

CARVALHO, D. M.; SOUZA, J. P. de. Análise da cadeia produtiva de caprino ovinocultura em Garanhuns. Rio Branco - Acre: SOBER, 2008, p. 17.

CNPQ. Conselho Nacional de Desenvolvimento Científico e Tecnológico. Diretório de grupos de pesquisa. Acesso em: 26 abr. 2010.

DAVIS, J. H.; GOLDBERG, R. A. A Concept of Agribusiness. Boston: Harvard UniversityGraduate School of Business Administration, 1957. 


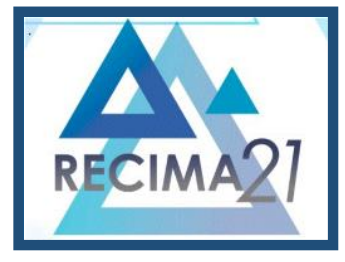

\section{RECIMA21 - REVISTA CIENTÍFICA MULTIDISCIPLINAR}

ENSINO DA CADEIA PRODUTIVA DA CARNE OVINA E CAPRINA: RELATO DE EXPERIÊNCIA DE UMA
PRÁTICA PEDAGÓGICA NO ENSINO REMOTO
Francisca Giselle da Cruz, Maria Aparecida Ferreira Barbosa Fernandes, Marcia Leyla de Freitas Macedo Felipe,
Daniela Glicea Oliveira da Silva, Priscila Izidro de Figueirêdo

DIAMOND, J. Evolution, consequences and future of plant and animal domestication. Nature, v. 418, p. 700-707, 2002.

DIAS, R. A.; LEITE, L. S. Educação a Distância: da legislação ao pedagógico. Petrópolis-RJ: Editora Vozes, 2010.

FRANCO, M. A. R. S. Prática pedagógica e docência: um olhar a partir da epistemologia do conceito. Rev. bras. Estud. pedagog. (on-line), Brasília, v. 97, n. 247, p. 534-551, 2016.

FREIRE, P. Pedagogia da Autonomia: saberes necessários à prática educativa. São Paulo: Paz e Terra, 1996.

FREIRE, P. Pedagogia da Autonomia: saberes necessários à prática educativa. São Paulo: Paz e Terra. 1997.

GIL, A. C. Didática do ensino superior. São Paulo: Atlas, 2008.

GOEDERT, L.; ARNDT, K. B. F. Mediação pedagógica e educação mediada por tecnologias digitais em tempos de pandemia. Criar Educação, Criciúma, v. 9, n. 2,p. 18, Edição Especial, 2020.

HAGUENAUER, C. J.; LIMA, L. G. R.; CORDEIRO FILHO, F. Comunicação e interação em ambientes virtuais de aprendizagem. In.: CONGRESSO INTERNACONAL DE EDUCAÇÃO A DISTÂNCIA, 16, 2010, Foz do Iguaçu. [Anais...], Foz do Iguaçu: ABED, 2010,p. 11.

HODGES, C.; MOORE, S.; LOCKEE, B.; TRUST, T.; BOND, A. The difference between emergency remote teaching and online learning. Disponível em: https://er.educause.edu/articles/2020/3/thedifference-between-emergency-remoteteaching-and-online-learning. Acesso em: 11 maio 2020.

IBGE. Instituto Brasileiro de Geografia e Estatística. Dados Estatísticos e Censo Agropecuário. Disponível em: www.ibge.gov.br. Acesso em: 08 out. 2020.

IFAD. International Fund for Agricultural Development. Rural Poverty Report. New realities, new challenges: new opportunities for tomorrow's generation. [S. I.]: Rome, 2010.

IFCE - Instituto Federal De Educação, Ciência E Tecnologia Do Ceará. Portaria

n³18/GABR/Reitoria, de 16 de março de 2020. Fortaleza: SEI/IFCE, 2020.

IFCE - Instituto Federal De Educação, Ciência E Tecnologia Do Ceará. Resolução n 007, de 10 de março de 2010. Fortaleza: SEI/IFCE, 2020.

IFCE - Instituto Federal De Educação, Ciência E Tecnologia Do Ceará. Resolução n²9, 08 de agosto de 2014, do CONSUP/IFCE. Fortaleza: SEI/IFCE, 2014.

IFCE - Instituto Federal De Educação, Ciência E Tecnologia Do Ceará. Resolução n 67, de 31 de julho de 2017. Fortaleza: SEI/IFCE, 2017.

LIMA, L. C. C. Análise das práticas docentes de planejamento e mediação em redes sociaisno ensino médio. 2011. 146 f. Dissertação (Mestrado em Ciências da Computação) - Universidade Federal de Pernambuco, Pernambuco, 2011.

MACHADO, P. L. P. Educação em tempos de pandemia: O ensinar através detecnologias e mídias digitais. Revista Científica Multidisciplinar Núcleo do Conhecimento. Ano 05, v. 8, p. 58-68, 2020. 


\title{
RECIMA21 - REVISTA CIENTÍFICA MULTIDISCIPLINAR
}

\author{
ENSINO DA CADEIA PRODUTIVA DA CARNE OVINA E CAPRINA: RELATO DE EXPERIÊNCIA DE UMA \\ PRÁTICA PEDAGÓGICA NO ENSINO REMOTO \\ Francisca Giselle da Cruz, Maria Aparecida Ferreira Barbosa Fernandes, Marcia Leyla de Freitas Macedo Felipe, \\ Daniela Glicea Oliveira da Silva, Priscila Izidro de Figueirêdo
}

MARCONI, M. A.; LAKATOS, E. M. Fundamentos de metodologia científica. 5. ed. São Paulo: Atlas, 2006.

NOGUEIRA FILHO, A.; ALVES, M. O. Potencialidades da cadeia produtiva da ovinocaprinocultura na região Nordeste do Brasil. Banco do Nordeste do Brasil. Escritório técnico de estudos econômicos do Nordeste - ETENE, 2002.

PENTEADO, H. D. Professores de prática pensando a didática: considerações sobre uma vivência. In: EDUCAÇÃO \& SOCIEDADE/CEDES, Campinas, n. 21, p.07-12, 1988.

PESSOA, R. M. S.; GOIS, G. C.; COSTA, D. C. C. C.; SILVA, A. P.R. SANTOS, R. N. Nutritime Revista Eletrônica, Viçosa, v. 16, n. 01, p.8364-8369, jan/fev. 2019. ISSN: 1983-9006.

PROCHNIK, V. Cadeias produtivas e complexos industriais (parte do Cap. 2 Empresa, indústria e mercados). In.: HASENCLEVER, L.; KUPFER, D. (Ed.). Economia Industrial: osfundamentos teóricos e práticas no Brasil. 2. ed. Rio de Janeiro: Campus, 2013.

REGUEIRO, M. M. L.; VASCONCELOS, E. E.; BELLUZZO, S. S. Ensino mediado por tecnologias no curso de Fisioterapia do Centro Universitário Barão de Mauá durante operíodo de pandemia da COVID-19. In.: Revista Interdisciplinar de Saúde e Educação Ribeirão Preto, v. 1, 2020. ISSN 2675-4827.

ROSANOVA, C. Fatores favoráveis e limitantes ao desenvolvimento da cadeia produtiva da ovinocaprinocultura de corte no Brasil. 2004. 42 f. In.: Trabalho de Conclusão de Curso(PósGraduação) - Curso de Pós-Graduação Lato Sensu em Gestão Agro Industrial, Universidade Federal de Lavras, Lavras, 2004.

ROSSATO, R. Século XXI: saberes em construção. Passo Fundo: UPF, 2002.

SILVA, R. R. O agronegócio brasileiro da carne caprina e ovina. Salvador-BA: R. R. da Silva, 2002, p. 111.

SÓRIO, A.; RASI, L. Ovinocultura e abate clandestino: um problema fiscal ou umasolução de mercado?. Revista de Política Agrícola, v.19, p. 71-83, 2010.

SOUSA, W. H. D. O Agronegócio da Caprinocultura de Corte no Brasil. Tecnologia \&Ciência Agropecuária, v. 1, p. $51-58,2007$.

TARDIF, M. Saberes docentes e saberes docentes e formação profissional.Petrópolis: Vozes, 2002.

XIMENES, L. J. F.; CUNHA, A. M. da. Setor de Peles e de couros de caprinos e de ovinos no Nordeste. Banco do Nordeste, Ano VI, n. 1, p. 22, mar. 2012. 